\title{
REPORT ON THE OPHTHALMIC DEPARTMENT, LEMNOS
}

\author{
BY \\ F. LOCKHART GIBSON, \\ MAJOR, A.I.F. \\ OPHTHALMOLOGIST, 3RD AUSTRALIAN GENERAL HOSPITAL.
}

FOR a short period the eye cases were distributed throughout the Hospital, and were treated by me in the wards in which they happened to be. Next, a single marquee tent was allotted to me. After the first week in September, the department became established in three marquees. Two of these were always available for in-patients, and the third was used as a consulting and ophthalmoscopic room, a portion being divided off as a waiting room for out-patients. Later on another marquee was added and filled for a time with patients.

During the last part of our sojourn at Lemnos, a hut ( 24 feet by 10 teet) was erected for my consulting room. Haab's giant magnet was, after that, utilized there instead of in the operating room.

My services, by direction, were made available to all the other hospitals and units on the island, as well as to those on the ships in the bay. Many Greek villagers also consulted me. The out-patient clinique, which averaged some twenty patients daily, supplied some of the in-patients for the wards.

Owing to Major Kent Hughes's absence and illness, I had also to undertake the ear, nose, and throat work; but by the end of September, it was found impossible to cope with the out-patients, and Captain Anderson saw them for me. I continued merely as consultant, and saw any unusual or acute cases with him, and other officers. There were always some ear and throat cases in the eye wards, chiefly tonsillitis and acute or sub-acute otorrhœa. An isolation tent was subsequently added, so that doubtful throat cases were not admitted into the wards.

The records of 126 eye cases have been preserved; I am of opinion that a good many have gone astray.*

These are first separated into two large groups, viz.: (1) cases neither directly nor indirectly attributable to explosive weapons, and (2) those attributable either directly or indirectly to explosive weapons-included in these are shrapnel, bombs, and bullets and in the indirect injuries, excoriations of the conjunctiva and cornea from

\footnotetext{
"Compared with the work of the department at Abbassia, the numbers of in-patients are small. More ophthalmic cases were admitted in a month at Abbassia than in four months at Lemnos, but a majority of the cases admitted at Abbassia would have been treated as out-patients at Lemnos. All admitted at Lemnos required hospital treatment. At Abbassia, conjunctivitis, cases requiring correcting glasses, and cases admitted only for " boarding" had to be kept in hospital.
} 
parapet sand and gravel and the impaction of fragments of sand and gravel in the cornea. In each group rather more than 60 cases will be found, practically dividing them equally.

To classify them into anatomical groups, an additional group for foreign bodies in the eye and another for enucleations must be added. It is found that no case of much importance falls outside one or other of these groups. As many eyes received more than one injury such grouping brings the number of cases up to 200 or more.

(1) Conjunctiva, 44 ; (2) cornea, 51 ; (3) iris, 11 ; (4) lens, 13 ; (5) vitreous and fundus, 13 ; (6) sclerotic, 7 ; (7) lids, 8 ; (8) orbit, 5 ; (9) anterior chamber, 4 ; (10) foreign bodies, 30 ; (11) enucleations, 14.

Foreign Bodies. - To refer briefly to the most interesting points in these groups of cases, but departing from the order above given: there were 14 intra-ocular foreign bodies, if we include 2 which were within the sclerotic coat, but perhaps not within the choroid. Of these, 6 were removed: 3 from the anterior chamber; 1 through the wound in the sclerotic from the vitreous chamber close to it. In this case, a piece of steel, was not from an explosive weapon; 2 from within the sclerotic, but probably not within the choroid. 6 foreign bodies were left in situ.

Of the 6 cases from which intra-ocular foreign bodies were removed, 4 see as well as before; one sees 6/18 only, because small erosions on the cornea have interfered with its transparency; one has an absorbing traumatic cataract, and may require discission.

Of the 6 eyes retaining their foreign bodies, 2 have useful sight, viz., 6/12 and 6/18; one may regain sight after the lens has been absorbed, subsequent to further discission; one has no sight; one has no sight, and the eye will probably have to come out; one patient, a Greek, refused to have the eye removed, although warned of the possible danger to the other eye. It contained two foreign bodies, had a partial traumatic cataract, counted fingers, but showed ciliary irritation at times. The giant magnet failed to attract the foreign bodies.

The remainder of the thirty eyes amongst in-patients which contained foreign bodies, included foreign bodies in the cornea and under the scleral conjunctiva. Several of the eyes had more than one foreign body. Many foreign bodies were removed from out-patients who continued to be treated, if necessary, as out-patients. A peculiarity of the foreign bodies in the cornea was their depth. Many had practically reached Descemet's membrane, and it was with the greatest difficulty that they were removed. A spud in many cases was not sufficient, the point of a Graefe's knife being necessary. Another peculiarity was the minute size of many of the intruding substances. Their size and depth demonstrated the great force with 
which they had been projected. (In civil practice, small fragments do not come with sufficient force to be embedded deeply in the cornea.) They were composed of steel, lead, nickel, and sand or gravel. The eyes in all cases did well, but the foreign bodies left permanent minute opaque scars.

Two fair-sized foreign bodies were found in the orbit, one, a piece of steel, had entered at the inner end of the eyebrow and was detected by the X-rays under the roof of the orbit, fairly far back. The giant magnet pulled it forward under the conjunctiva of the upper fornix, and then, on everting the lid, pulled it, without an incision being necessary, across an inch of space. The other foreign body had grooved the edge and conjunctival surface of the lower lid. The scar had healed, but there was discomfort in turning the eye up. An X-ray examination detected the foreign body above the floor of the orbit fairly far back. The giant magnet failed to cause any feeling of discomfort or to attract the foreign body. The discomfort gradually subsided, and the man rejoined his unit, retaining the foreign body, with unaffected sight.

The fourteen enucleations were of eyes injured by projectiles. They all did well, although several had other injuries in addition to the eye injury.

In no case had I to remove both eyes, but in one case the remaining eye was badly injured, and its retina became detached. It is blind, but may be kept, and is not disfigured.

In another, the second eye, like the one removed, also contained pieces of wood, and it will almost certainly require to be enucleated, although the pieces of wood were removed.

Conjunctiva.-All the pterygia (8) were large ones, and all in members of the A.I.F., except in one case. These growths were removed. The lower half was cut away entirely, and the upper half detached, turned downwards and fixed in the wound so left, a method introduced, I believe, by Thos. Evans, of Sydney, and used by me for many years when the pterygium was a large one. It ensures against return, and should be the operation of choice.

Only one case had to have both eyes operated on.

A severe case of symblepharon had been operated on in England, with bad result, by transplantation of skin. A graft of buccal mucous membrane transplanted, after removing the scar and the bunched-up skin, held, and a good result was obtained.

Cornea.-The cases of corneal ulceration were due to injury, to phlyctenular inflammation, and to the results of acute conjunctivitis of a catarrhal nature. There were no cases of gonorrhœal ophthalmia.

Three cases due to injury proved to be severe infective spreading ulcers, accompanied by hypopyon and chemosis. One I failed to arrest, even with the electro-cautery. The eye had to be removed. One, in a Greek, where the ulcer occupied fully $2 / 3$ of the 
cornea, with hypopyon, and chemosis, was arrested by the electrocautery. Subsequent optical iridectomy gave the eye useful sight. The third case, in which the ulcer was smaller, but the chemosis extreme and the hypopyon very marked, responded quickly to the electro-cautery and regained excellent sight.

.Lens.-Injuries to the lens were accompanied by other injuries to the eyes. Amongst out-patients there were some peculiar lens opacities which may not have been congenital, but due to shell concussion. There were also a good many cases of ordinary congenital lamellar cataract amongst the English troops.

Iris.-Under the head of iris, were several cases with other injuries also. The five most interesting, were two operative and three iritis cases. Of the two operative cases, one was the Greek's eye abovementioned, the other an eye in a young officer suffering from intermittent attacks of glaucoma. It was due to a penetrating injury to the upper corneo-scleral margin "during child-birth." The pupil was occluded and drawn up. A very fine pin-point slit at the edge of the occluded pupil allowed imperfect intra-ocular circulation, but at times this became blocked, resulting in an attack of glaucoma, with high tension, a shallow anterior chamber and bulging iris. These attacks had been very frequent latterly, and were becoming severe. When comfortable, the eye had minus tension. During an attack, the tension was +1 . An iridectomy not only relieved him from attacks and produced normal tension, but also gave some sight to an eye which had never had more than bare perception of light. He counted fingers at several yards and may improve further. He was able to rejoin his regiment without fear of further attacks.

Of the three iritis cases, two proved to be rheumatic and one syphilitic. They were all severe, had occluded pupils and chemosis, and failed to count fingers. Massive doses of salicylate of soda (300 grains within 30 hours) together with 600 grains of citrate of soda, were followed by breaking-down of the adhesions, and continuance of treatment and of atropin led to quite satisfactory results and good sight. The syphilitic case responded perfectly to energetic mercurial inunction.

Fundus.-There were many interesting fundus cases and still more of them amongst the out-patients.

One lad who had been invalided back from Gallipoli had a central scotoma, due to a subhyaloid hæmorrhage at the macula. He was admitted, and after a few days, mild attacks of tertian malaria developed. This was confirmed by Major C. J. Martin's examination of the blood. He responded at once to quinine. The subhyaloid hæmorrhage may have been nothing more than a coincidence. The prognosis, judging from other cases of subhyaloid hæmorrhage, in my experience, is hopeful regarding sight. Another case of hæmorrhage 
in the fundus occurred in the Commanding Officer of another unit. He had several hæmorrhages into each retina and into one disc. No cause could be discovered. His urine was normal in every respect. It was surmised that the antiscorbutic or antiberiberi constituents of his diet may have been insufficient. He was treated accordingly and, of course, invalided home.

Remarks. - The conjunctival cases were catarrhal, phlyctenular, and traumatic inflammations, and pterygia. Only one specimen of catarrhal secretion was sent to the pathologist, and the report was negative. The cases were often severe and were frequent amongst the Greek population of the island, both in adults and children. Corneal ulceration was present in some of the Greeks and also in some of the troops when they came under observation. A lotion containing sulphate of zinc, gr. iii, and boric acid, gr. xii, to the ounce of water, acted practically as a specific. It caused improvement at once, and when the cases were not of long-standing, rapid cure resulted. Many catarrhal cases suffered also from phlyctenular conjunctivitis, and required, in addition, yellow oxide of mercury.

I met with no case of trachoma in Lemnos. The few seen had come from Egypt, or were recrudescences in Australians who had previously suffered.

Although I can only say that two foreign bodies were removed by the giant magnet, one from the interior of the eye and one from the orbit, which would have been difficult or impossible to remove without so strong a magnet as Haab's, the knowledge and help given by it in other cases were so great that I should have felt imperfectly equipped without it. Until it arrived, I had only a Hirschberg's hand electric magnet (8-volt dry cells), but it enabled me to remove one piece of steel from the anterior chamber. At least two cases might have been benefited had the giant magnet arrived sooner. The fact that the $\mathrm{X}$-rays also were not available during the first few weeks was a considerable handicap.

The failure of hospital boats to get transports, diminished the number of cases of injured eyes which should, according to orders, have come to me from Gallipoli.

Two things militated against the greater usefulness of the giant magnet, viz.: the time which always elapsed before the cases arrived at Lemnos, and the minute size of the foreign bodies. In the case of small bodies the force with which the magnet attracted them was slight, and consequently any plastic lymph anchoring them in the eye was able to hold them. This was clearly demonstrated in the case of a minute piece of steel lying between the lens and iris, and attached to each by lymph. The magnet failed to bring it into the pupil area. The lymph stretched, but did not relinquish its hold on the foreign body. It was eventually picked out of the anterior chamber by forceps after a small iridectomy. 
The only two eyes removed after failure to extract the contained foreign body by the giant magnet contained respectively a piece of lead and a piece of copper.

The out-patients who were supplied by other units and hospitals on the island, and by the ships in the bay, averaged about twenty a day, from 10 September to the first week in January. Notes of 1,004 new ophthalmic out-patients were taken during that time. A large number of these were cases of refraction, many of whom I found to be so benefited by glasses as to be made efficient, whereas before they could not have been so. Most of them stated that no attempt had been made in England to test their vision. 254 prescriptions for glasses were given. I found after a time that many of them were not made use of, and then refrained from giving prescriptions, unless the men or their N.C.O's. said those given would be sent to an optician. Latterly, the prescribing of spectacles was put on a very satisfactory basis, partly, I think, as a result of my representations to Surgeon-General Babtie. He ultimately prevailed on the War Office to supply the men with glasses, cylindrical or otherwise.

The routine which was proposed by Surgeon-General Babtie, after consultation with Lieut.-Colonel H. L. Eason, who had also discussed the question with me, and which was adopted during my last few weeks in Lemnos, may be expected to meet all objections to ordering and supplying spectacles to the troops. It was as follows.-Prescription to be sent to the base department at Alexandria, to be entered in the last page of the man's pay book, together with a statement of his vision, without and with correction. Two pairs of spectacles to be sent to the man's O.C. Breakages or loss to be supplied by the man himself, and without his return to any base.

Major Herschell Harris gave me most valuable help by taking $\mathrm{X}$-ray pictures of eyes and foreign bodies or possible foreign bodies.

Owing to the generosity of the Queensland Red Cross Society, which cabled me $£ 200$ to London for the purpose of equipping my department, I was able to get all the instruments I required, including a Haab's magnet.

\section{Appendix}

1. Intra-ocular foreign body. - A young officer had suffered from several wounds from a bomb explosion. One piece had entered the sclerotic of the right eye on its inner side, behind the ciliary region, and passed backwards through the vitreous, into the sclerotic coat or through it and just to outside. In spite of the blood in the vitreous chamber, it was possible to see the posterior wound in the coats, situated above and to the inner side of the disc, but no foreign body could be detected. The $\mathrm{X}$-rays located the foreign body either in the eye or just outside the coats in the neighbourhood 
of the posterior wound. The giant magnet failed to attract it from the orbit or through the re-opened wound, or to cause any sensation of discomfort. The pieces of metal found elsewhere in his body were steel. He regained $6 / 12$ of vision-of course, with a scotoma in the position of the posterior injury. The conclusion come to was that the foreign body had at least got as far as the sclerotic and possibly just through it, and that there was a fair possibility of the eye not suffering further.

2. Case of left Homonymous Hemianopsia.-I was asked by Colonel Sir Alexander McCormack to see this case just prior to trephining. He will report it elsewhere fully himself. The injury, a bullet wound, was in the right occipital lobe in the angle formed by the longitudinal sinus and the lateral sinus. Direct injury was done to the right occipital lobe, apparently chiefly, if not entirely, to its mesial portion. Prior to operation, he had complained of bilateral left hemianopsia and a very small right field. The result supported the conclusion that the left occipital lobe on its mesial aspect had not suffered directly but indirectly from shock and from the pressure of the hæmorrhage on the mesial part of the right occipital lobe. After recovering from the operation, he had word-blindness for a week or two, not letter-blindness, then his visual word memory centre gradually reasserted itself, and he regained the power of reading words. His right field, which was very contracted, gradually improved, and was improving when he left Lemnos. There were no changes in either fundus at any time. The left hemianopsia persisted, as was expected.

3. Three bullet wounds of the orbit.-(a) Another case of Sir Alexander MacCormack's was subsequently transferred to my care, when the trephine wound was nearly healed. The bullet had entered the frontal bone above the temporal region on the left side and passed out at the angle of the right lower jaw. The case was trephined, but one or two small fragments of the inner table were not removed at the initial operation. The left eye was very proptosed with considerable chemosis and solid œdema of the lids, but neither lids nor conjunctiva showed at first or later any signs of blood extravasation. The external ocular muscles were all paralysed, even the orbicularis; apparently more by the solid œdema than by direct interference with nerve supply. There was no optic neuritis nor alteration in the vessels of the fundus, until nearly two months afterwards, when optic atrophy began to show at the disc. The external ocular muscles all recovered. Cosmetically, the eye will be excellent. It will not worry the other, but it will have no sight. The odema and paralysis did not finally disappear until a fine spicule of the inner table was removed through the trephine wound some six weeks after the injury.

(b) In a case seen with Lieut.-Colonel Cudmore, and afterwards 
transferred to my care, the bullet had passed through the back of the orbit, and directly injured the posterior part of the globe. There were chemosis, proptosis, much ecchymosis in lids and conjunctiva, and some intra-ocular hæmorrhage. The proptosis and chemosis subsided. The eye did not inflame. Its tension became minus. It had, of course, no sight, but the man was able to go home with the eye in, although cosmetically not perfect, and somewhat shrunken. He was advised to have it removed later.

(c) Another bullet took an extraordinary course.-It pierced the right upper lid in its external third, passed out between the edges of the lids without wounding them, but after destroying the cornea, and indirectly the lens, pierced the skin again where the lower lid joined the cheek, passed through the right nostril and the floor of the left nostril, and out through the upper lip below the left nostril. The right eye was removed on admission.

4. Traumatic myopia.-A soldier on the island injured his right eye while chopping wood. The lens was dislocated forward, making the anterior chamber shallow, and causing five dioptres of myopia in a previously emmetropic eye. The lens remained clear, and with -5D. the eye saw 6/12. As I have observed twice before, complete accommodation was retained, although the ciliary muscle must have been ruptured.

5. Post-diphtheritic paralysis.-Swabs from the nasopharynges of two cases of paralysis of accommodation enabled both to be pronounced by the pathologist to be diphtheria carriers. The previous slight sore throats had not called for treatment in camp.

\section{FUNDUS LESIONS IN CASES OF WAR NEPHRITIS*}

\section{BY \\ J. JAMESON EVANS, BIRMINGHAM.}

THE Medical Research Committee is investigating selected cases of war nephritis, and among other particulars concerning which information is desired, is the state of the fundus oculi. In the course of my examination of these cases at the First and Second Birmingham War Hospitals I found certain fundus changes which suggested to me that if ophthalmoscopic investigations were to be of any help to the Committee, we should have to examine every case of war nephritis, and the results obtained by different observers should be then examined in order, if possible, to decide whether this particular form of nephritis causes, or is associated with, changes in

\footnotetext{
*Communicated to the 1917 Congress of the Ophthalmological Society of the United Kingdom. The full article will be published in the Society's Transactions.
} 